\title{
ASO Author Reflections: Percutaneous Hepatic Perfusion with Melphalan in Patients with Unresectable Hepatic Metastases from Ocular Melanoma
}

\author{
T. Susanna Meijer, MD $(1)$, and Mark C. Burgmans, MD, PhD \\ Department of Radiology, Leiden University Medical Center, Leiden, The Netherlands
}

\section{PAST}

Up to $50 \%$ of patients with ocular melanoma will develop metastatic disease with predominant liver involvement. Because effective systemic treatments are lacking, liver-directed therapies play a key role in the management of these patients. The superiority of percutaneous hepatic perfusion with melphalan (M-PHP) over best available care in controlling liver disease has been demonstrated in a randomized, controlled trial. ${ }^{1}$ In this study, approximately $40 \%$ of patients had extrahepatic disease and M-PHP was associated with high rates of hematologic toxicity. To reduce the rate of hematologic toxicity following M-PHP, a new hemofiltration system with a second-generation detoxification cartridge (GEN 2 filter) was developed. So far, only retrospective studies have been published on this subject. ${ }^{2-4}$

\section{PRESENT}

This prospective, phase II study investigated the efficacy and safety of M-PHP using the GEN 2 filter in well-selected patients with unresectable metastases from ocular melanoma confined to the liver. ${ }^{5}$ Sixty-four M-PHP procedures were performed in 35 patients. The overall response rate of $72 \%$ (complete response $3 \%$, partial

T. Susanna Meijer and Mark C. Burgmans have contributed equally to this work.

(C) The Author(s) 2020

First Received: 16 June 2020;

Published Online: 18 July 2020

T. S. Meijer, MD

e-mail: t.s.meijer@lumc.nl; susannameijer@gmail.com response 69\%) and median overall survival (OS) of 19.1 months in the current study appeared to be more favourable compared with published data on other treatment modalities and provide convincing evidence for the efficacy of M-PHP in metastatic ocular melanoma. Furthermore, responders demonstrated a significantly longer median OS than nonresponders (27.5 vs. 11.9 months, $p<0.001$ ). M-PHP is a well-tolerated procedure with an acceptable safety profile.

\section{FUTURE}

Seventy-four percent of patients in this study developed extrahepatic metastatic disease during follow-up. This indicates that many patients with ocular melanoma will suffer from systemic spread for which liver-directed therapy is only a temporarily solution. We recently started a phase I/II study investigating combination therapy of M-PHP + ipilimumab/nivolumab to better control both hepatic and extrahepatic disease (CHOPIN trial, NCT04283890). Future research should try to reproduce abovementioned results in a large, multicenter trial and to develop standardized patient selection criteria.

DISCLOSURE The Leiden University Medical Center received financial support (no grant number applies) and in kind contributions from Delcath Systems Inc, New York, NY, for conducting this study. The authors declare that Delcath Systems Inc. had no involvement in any part of the study.

OPEN ACCESS This article is licensed under a Creative Commons Attribution 4.0 International License, which permits use, sharing, adaptation, distribution and reproduction in any medium or format, as long as you give appropriate credit to the original author(s) and the source, provide a link to the Creative Commons licence, and indicate if changes were made. The images or other third party material in this article are included in the article's Creative Commons licence, unless indicated otherwise in a credit line to the material. If material is not 
included in the article's Creative Commons licence and your intended use is not permitted by statutory regulation or exceeds the permitted use, you will need to obtain permission directly from the copyright holder. To view a copy of this licence, visit http://creativecommons. org/licenses/by/4.0/.

\section{REFERENCES}

1. Hughes MS, Zager J, Faries M, et al. Results of a randomized controlled multicenter phase III trial of percutaneous hepatic perfusion compared with best available care for patients with melanoma liver metastases. Ann Surg Oncol. 2016;23:1309-19.

2. Vogl TJ, Koch SA, Lotz G, et al. Percutaneous isolated hepatic perfusion as a treatment for isolated hepatic metastases of uveal melanoma: patient outcome and safety in a multi-centre study. Cardiovasc Interv Radiol. 2017;40:864-72.
3. Karydis I, Gangi A, Wheater MJ, et al. Percutaneous hepatic perfusion with melphalan in uveal melanoma: a safe and effective treatment modality in an orphan disease. J Surg Oncol. 2018;117:1170-8.

4. Artzner C, Mossakowski O, Hefferman G, et al. Chemosaturation with percutaneous hepatic perfusion of melphalan for liverdominant metastatic uveal melanoma: a single center experience. Cancer Imaging. 2019 30;19:31.

5. Meijer TS, Burgmans MC, de Leede EM, et al. Percutaneous hepatic perfusion with melphalan in patients with unresectable ocular melanoma metastases confined to the liver: a prospective phase II study. Ann Surg Oncol. https://doi.org/10.1245/s10434020-08741-x.

Publisher's Note Springer Nature remains neutral with regard to jurisdictional claims in published maps and institutional affiliations. 